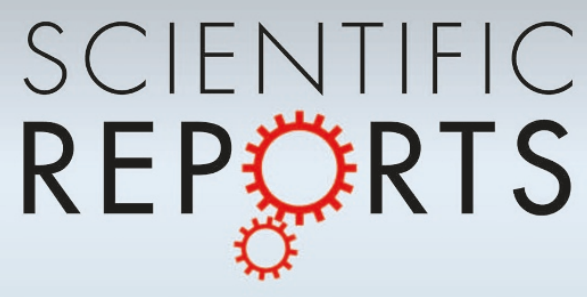

OPEN

SUBJECT AREAS:

BIOINSPIRED MATERIALS

MECHANICAL PROPERTIES

Received

27 February 2014

Accepted

19 June 2014

Published

7 July 2014

Correspondence and requests for materials should be addressed to

Y.L. (yanglu@cityu. edu.hk)

\section{Crack Propagation in Bamboo's Hierarchical Cellular Structure}

\author{
Meisam K. Habibi' \& Yang Lu' ${ }^{1,2}$
}

'Department of Mechanical and Biomedical Engineering, City University of Hong Kong, Hong Kong, China, ${ }^{2}$ Centre for Advanced Structural Materials (CASM), City University of Hong Kong, Hong Kong, China.

Bamboo, as a natural hierarchical cellular material, exhibits remarkable mechanical properties including excellent flexibility and fracture toughness. As far as bamboo as a functionally graded bio-composite is concerned, the interactions of different constituents (bamboo fibers; parenchyma cells; and vessels.) alongside their corresponding interfacial areas with a developed crack should be of high significance. Here, by using multi-scale mechanical characterizations coupled with advanced environmental electron microscopy (ESEM), we unambiguously show that fibers' interfacial areas along with parenchyma cells' boundaries were preferred routes for crack growth in both radial and longitudinal directions. Irrespective of the honeycomb structure of fibers along with cellular configuration of parenchyma ground, the hollow vessels within bamboo culm affected the crack propagation too, by crack deflection or crack-tip energy dissipation. It is expected that the tortuous crack propagation mode exhibited in the present study could be applicable to other cellular natural materials as well.

A s one of the most renewable resources on Earth, bamboo is the fastest-growing and highest-yielding natural cellular material, which reaches maturity within months and ultimate mechanical properties within few years ${ }^{1}$. Well known as a functionally graded hierarchical bio-composite, bamboo comprises three fundamental tissues named epidermis, vascular bundles and parenchyma ground. The thick epidermis is the shell of the bamboo whereas the vascular bundles are the longitudinal tissues supporting the whole bamboo, with the ground parenchyma occupies the rest of the organ. Within each vascular bundle, the role of vessels and phloem is to transport water and nutrients ${ }^{2}$ whereas they are all surrounded by fibers ${ }^{3}$ (see Fig. 1). In terms of volume fraction, the fibers and cellular parenchyma form the majority of bamboo culm (for Phyllostachys edulis species: $\sim 40-60 \%{ }^{4,5}$ and $\sim 20-60 \%{ }^{6,7}$, respectively, depending on location, local climate, age...); whereas vessels and phloem make up the reminder. In view of the weight-to-weight basis, tensile strength, Young's modulus, compressive strength and interlaminar shear of bamboo is reasonably comparable with conventional structural materials such as low carbon steel and fiber glass reinforced plastics ${ }^{8}$. So far, the interesting mechanical properties of bamboo have been mainly attributed to the presence of fibers within the bamboo culm ${ }^{8-10}$. However, for such a complicated hierarchical structure, one wishes to understand the role of other structural features, such as parenchyma cells and hollow vessels, on the mechanical performance of bamboo. And getting a deep understanding on bamboo's hierarchical features, particularly at cellular level, can be quite helpful in designing biomimetic polymeric, metallic composites.

Although a lot of attempts have been made, so far, to investigate the functionally graded structure along with bulk properties of bamboo ${ }^{4,5,8-14}$, very few attempts have been made to investigate the crack growth mode along with fracture mechanisms at micro-scale or cellular level. Among those earlier efforts, Shao et. al. ${ }^{14}$ explored the behavior of interlaminar fracture using double cantilever beam specimens, and basically illustrated that the crack propagation develops along the longitudinal interface between the fibers and ground tissue. In another attempt by Low et. al. ${ }^{8}$, the excellent damage tolerance of bamboo was attributed to the interlay and simultaneous presence of crack deflection, fiber debonding and crack bridging as the major energy dissipative processes. Similarly, Tan et. al. ${ }^{10}$ demonstrated that, in the course of bending deformation on a single edge notched specimen, the crack growth occurs by deflection into interlaminar boundaries. Pertaining to the studies conducted earlier, it is likely that the interaction between a developed crack with functionally graded fibers has been paid great attention to; whereas the role of cellular parenchyma ground along with presence of hollow vessels within the bamboo culm have been largely neglected. However, in light of considerable volume fraction of parenchyma cells along with hollow vessels ( $\sim 57.3 \pm 2.5 \%$ and $\sim 5.6 \pm 0.8 \%$, respectively, from our samples' microstructure analysis, see Methods), it is reasonable to speculate that the bamboo's remarkable mechanical behavior could be also stemmed out from the cellular configuration of parenchyma ground along with the possible crack interaction with hollow vessels. So in 
the present study, we will focus on investigating the interactions of not only bamboo's fibers but also parenchyma ground alongside hollow vessels with developed cracks, in a holistic approach, to obtain a comprehensive understanding of the underlying mechanisms for bamboo's superior fracture toughness ${ }^{15}$.

\section{Results}

Microhardness indentation-induced crack growth. To investigate the interaction of different constituents of bamboo (see Fig. 1) with a developed crack, a crack was intentionally initiated by microhardness indentation along the radial direction (RD) of bamboo culm (see Fig. 2). Our microstructural investigations conducted on an indentation-induced crack (see Fig. 3a) clearly demonstrated that, once the initiated crack reached the critical condition for further crack growth, it propagated along the parenchyma cells' boundaries (see Figs. $3 b-c$ and i). The exhibited crack growth mode continued as long as the crack was approaching the fibers' bundles. Similarly, within individual fibers' bundles, the crack propagated further through the interfacial areas (see Figs. 3d-e and i). Pertaining to the exhibited microhardness-induced crack growth along the RD (Fig. 3), it was shown that the crack was mostly deflected by an average deflection angle $(\theta)$ of $\theta_{\mathrm{RD}} \sim 25^{\circ}-60^{\circ}$ and $\theta_{\mathrm{RD}} \sim 45^{\circ}-60^{\circ}$ owing to the occurrence of interfacial fractures within the cellular parenchyma matrix and honeycomb fibers' bundles, respectively. Investigations further revealed that, in addition to cellular parenchyma matrix along with honeycomb fibers' bundles, the hollow vessels within bamboo culm could additionally affect the crack growth (see Fig. 3a): as cases demonstrated in Figs. 3f-h, the hollow vessel clearly deflected the crack and dissipated its driving energy. In fewer cases where cracks were not deflected and eventually entered into the hollow vessels, the vessels were essentially functioning as a crack-tip energy absorber. In either scenario (Fig. 3i), the vessels could effectively enhance the fracture toughness, not mentioning that the considerable volume fraction of hollow vessels also reduce the overall weight of bamboo.

Tension-induced crack growth. To further validate the exhibited crack growth mode in the longitudinal direction (LD) of bamboo culm, tensile tests were conducted on dog-bone shaped samples (without pre-notch), prepared from bamboo's longitudinal sections (see Fig. 2a) to assess the interaction of different constituents with a tension-induced crack. Microstructural analysis conducted on the tensile deformed samples, primarily, revealed that fibers' pull out (see Fig. 4a) was the most prominent feature in tensile fracture surfaces which could be simply correlated to the exhibited crack growth along the fibers' interfacial areas in both radial and longitudinal directions. More importantly, as displayed in Fig. 4b, the presence of those intact parenchyma cells was also regarded as a dominant feature in tensile fracture surfaces, which could be naturally attributed to the interfacial fracture within the cellular parenchyma ground, in the course of tensile loading. Similar to exhibited crack deflection along RD during microhardness indentation, the crack deflection angle $\left(\theta_{\mathrm{LD}}\right)$ along the $\mathrm{LD}$, owing to tensioninduced interfacial fracture, was estimated to be almost $\sim 90^{\circ}$ in average (see Fig. 4c) within both parenchyma matrix and fibers' bundles here.

In view of the compatibility amongst the interaction of different constituents of bamboo with both indentation/tension-induced cracks (see Figs. 3-4), it can be concluded that the cellular parenchyma ground along with honeycomb fibers accommodate the crack growth via their interfacial boundaries, and hollow vessels also contribute in changing the crack growth mode via either absorbing or deflecting the crack. Likewise, pertaining to the observed crack growth modes in the case of both indentation and tensile loading (see Fig. 3i and Fig. 4c), the crack deflection and propagation in real three-dimensional (3D) space can be therefore speculated: the indentation-induced crack exhibits the tortuous crack growth in bamboo's radial direction (RD); whereas the tension-induced crack demonstrates the crack growth in both radial (RD) and longitudinal (LD) directions. Together we have obtained a complete picture showing the interactions of bamboo's different constituents with a developed crack in a real bamboo culm structure.

\section{Discussion}

It is commonly known that, as a functionally graded bio-composite, the toughening of bamboo mostly happens during the crack growth and not in the course of crack initiation ${ }^{8,9,13}$. Hence, the more difficult is the crack growth, the higher is the fracture toughness. To date, the exhibition of bamboo's remarkable mechanical properties has mainly been attributed to the presence of fibers within the bamboo's culm $^{8,9,13}$. To get a quantitative understanding of the property difference among bamboo's different phases, we also performed microand nano-mechanical characterizations on bamboo's individual constituents and confirmed that, fibers are indeed the strongest phase (elastic modulus $\mathrm{E}_{\mathrm{f}}=22.8 \pm 2.8 \mathrm{GPa}$ by nanoindentation and $\mathrm{E}_{\mathrm{f}}=30.1 \pm 3.0 \mathrm{GPa}$ by micro-tensile testing; tensile strength $\sigma_{\mathrm{f}}=\sim 1000 \pm 300 \mathrm{MPa}$; see Methods) whereas parenchyma cells are comparatively weaker (elastic modulus $\mathrm{E}_{\mathrm{p}}=3.7 \pm 0.4 \mathrm{GPa}$ by nanoindentation). However, our experimental observations on fractured samples strongly suggested that the cellular configuration of parenchyma ground along with presence of hollow vessels within the bamboo culm (with their considerable volume fractions $\sim 57.3 \pm$ $2.5 \%$ and $\sim 5.6 \pm 0.8 \%$, respectively) should be also responsible for the bamboo's remarkable fracture toughness (averagely $\left.56.8 \mathrm{MPa} \cdot \mathrm{m}^{\frac{1}{2}}\right)^{15}$ : the exhibited interfacial fracture within the cellular parenchyma matrix along with honeycomb structure of fibers revealed that the interfaces of parenchyma cells as well as that of fibers were sufficiently weaker compared to the fracture toughness of both parenchyma cells and fibers themselves, respectively. Pertaining to the demonstrated interfacial fracture, the high fracture toughness of bamboo could be partly justified. The prevailed tortuous crack growth mode effectively increased the final fracture surface which consequently amplified the driving energy required. Likewise, the remarkable fracture toughness could be also attributed to the presence of hollow vessels within the bamboo culm as they could either deflect the crack growth direction or absorb the crack-tip energy (see Fig. 3a and 3i). Hollow vessels should be of high significance as their presence greatly reduces the overall weight of bamboo, whereas in view of the geometry and configuration, their function as a stress raiser in the course of loading is unlikely.

In view of the exhibited tortuous crack growth mode both in $\mathrm{RD}$ (see Fig. 3i) and LD (see Fig. 4c), the reduction in driving force for crack propagation, owing to both occurrence of interfacial fracture and crack tips' interaction with hollow vessels, can be likewise justified by a geometry-dependent model proposed by Hanlon and Suresh et. al. ${ }^{16,17}$ for polycrystalline materials: considering the exhibited crack growth mode, it is assumed that the cellular bamboo structure was mostly experiencing the mode I crack opening in the course of loading ${ }^{14}$ and any deviation of the crack away from the mode I growth plane (straight crack growth) led to a mixed loading mode at the tip of the $\operatorname{crack}^{16}$. In the case of the exhibited tortuous crack growth in both radial (RD) and longitudinal (LD) directions, it is assumed that the crack kinked at an average angle inclined $\theta$ with respect to the mode I plane. So, the local effective stress intensity factor at the tip of the crack could be then approximated by ${ }^{16}$ :

$$
\mathrm{K}_{\mathrm{eff}}=\cos ^{2}\left(\frac{\theta}{2}\right) \mathrm{K}_{\mathrm{I}}
$$

According to the equation, comparing to the case of having a straight crack growth $\left(\mathrm{K}_{\mathrm{I}}\right)$, the crack deflections, owing to either occurrence of interfacial fracture among parenchyma cells $\left(\theta_{\mathrm{RD}} \sim\right.$ 
(a)

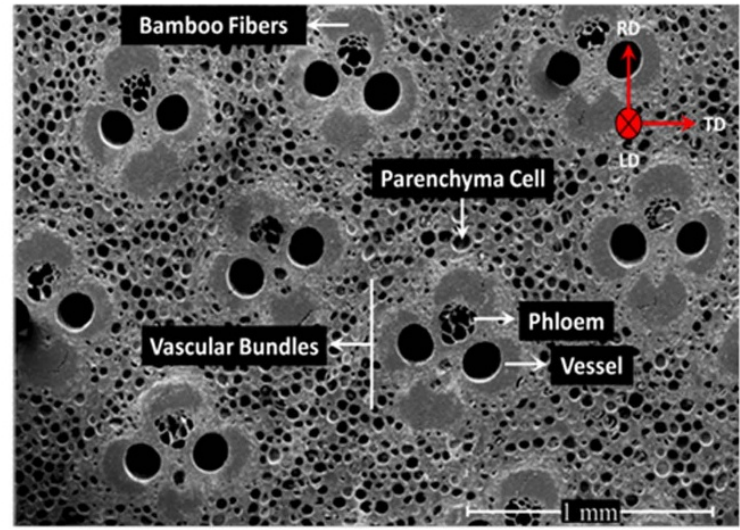

(c)

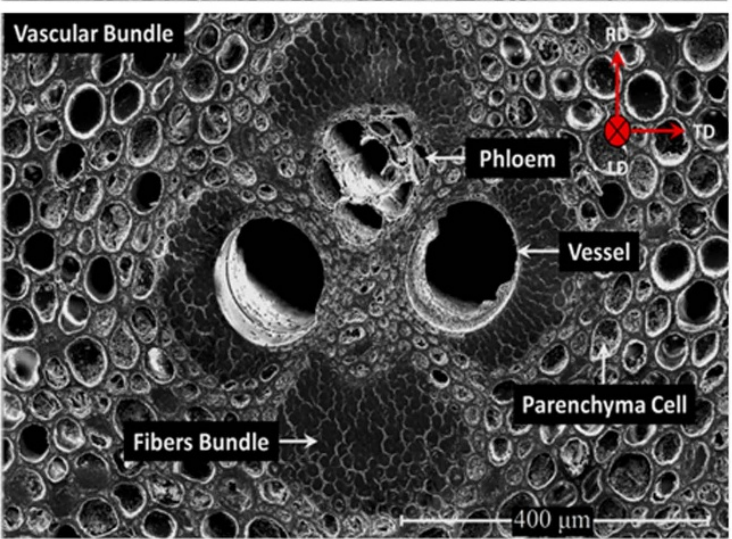

(e)

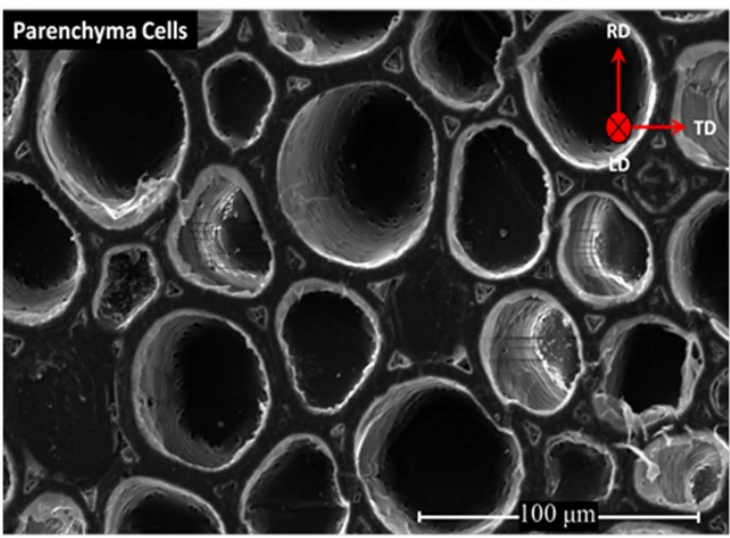

Bamboo Fibers

RD

(g)

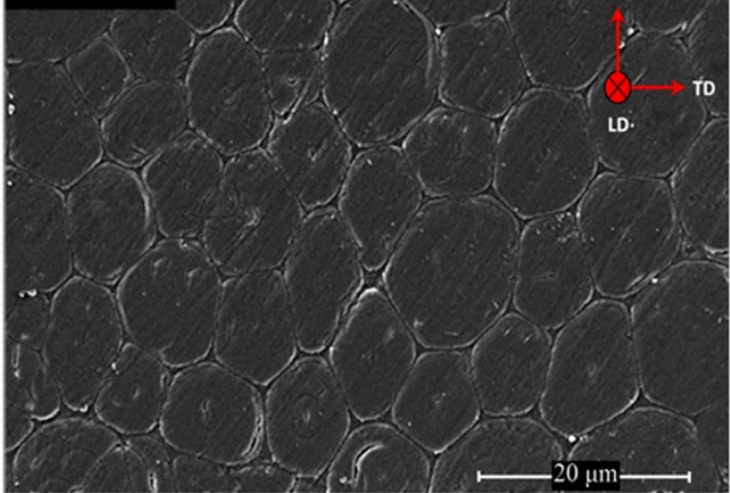

(b)

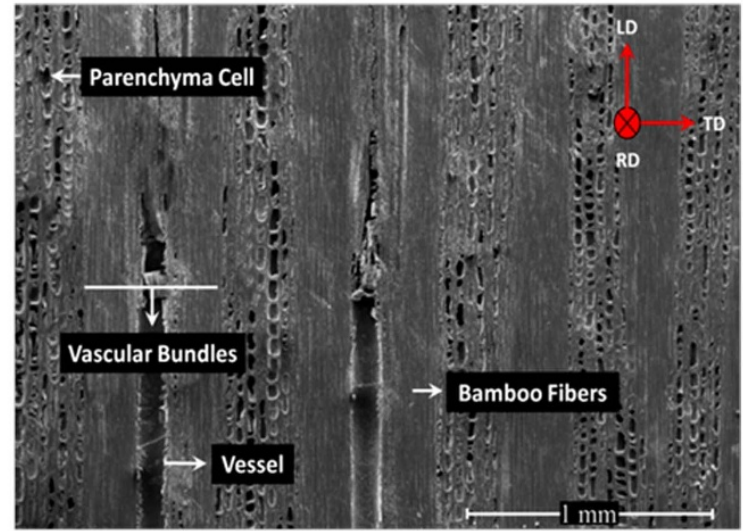

(d)

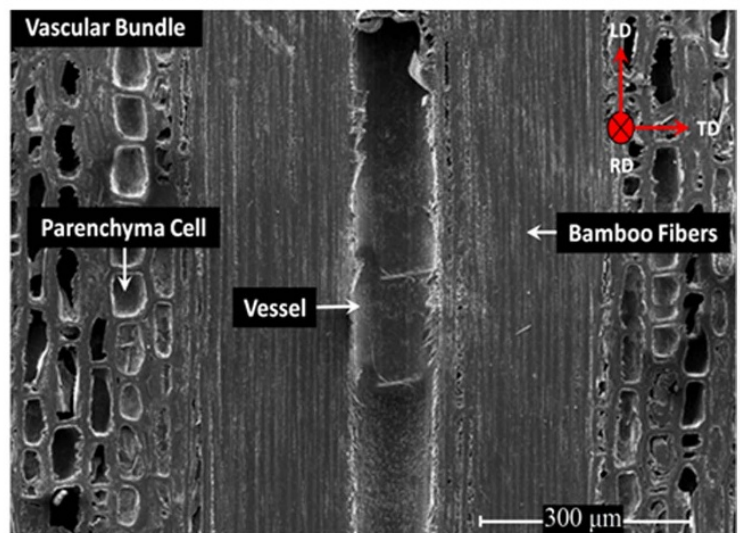

(f)
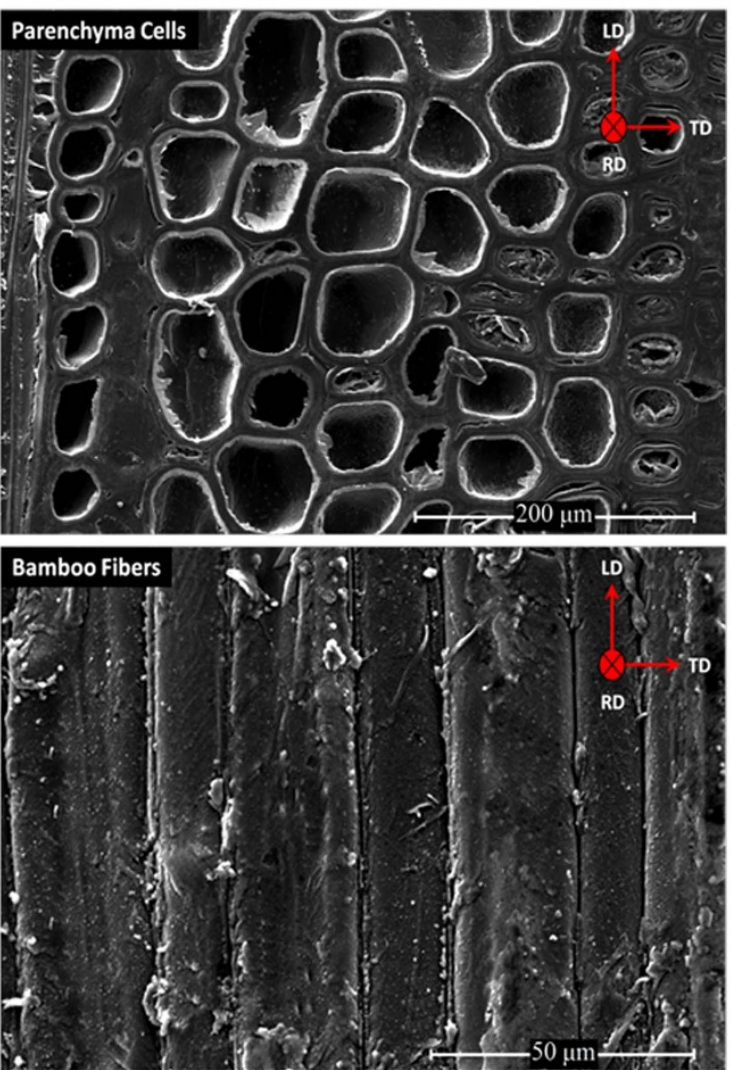

Figure 1 SEM micrographs of the raw bamboo culm with different constituents. zoom-in views of bamboo's vascular bundles along with the parenchyma ground and bamboo fibers along the transversal ((a), (c), (e) and (g)) and longitudinal ((b), (d), (f) and (h)) directions. As displayed, fibers and parenchyma cells, comparably, possess the majority of bamboo culm whereas vessels possess less contribution.

$\left.25^{\circ}-60^{\circ} ; \theta_{\mathrm{LD}} \sim 90^{\circ}\right)$ and fibers $\left(\theta_{\mathrm{RD}} \sim 45^{\circ}-60^{\circ} ; \theta_{\mathrm{LD}} \sim 90^{\circ}\right)$ or interaction with hollow vessels ( $\theta$ varies according to the vessel curvatures), would apparently reduce the overall driving force for further crack propagation ${ }^{16}$. This can be simply realized as the effective stress intensity factors $\left(\mathrm{K}_{\text {eff }}\right)$ owing to crack deflections along the RD within the corresponding constituents $\left(\mathrm{K}_{\mathrm{eff}}(\mathrm{RD})\right)$, 


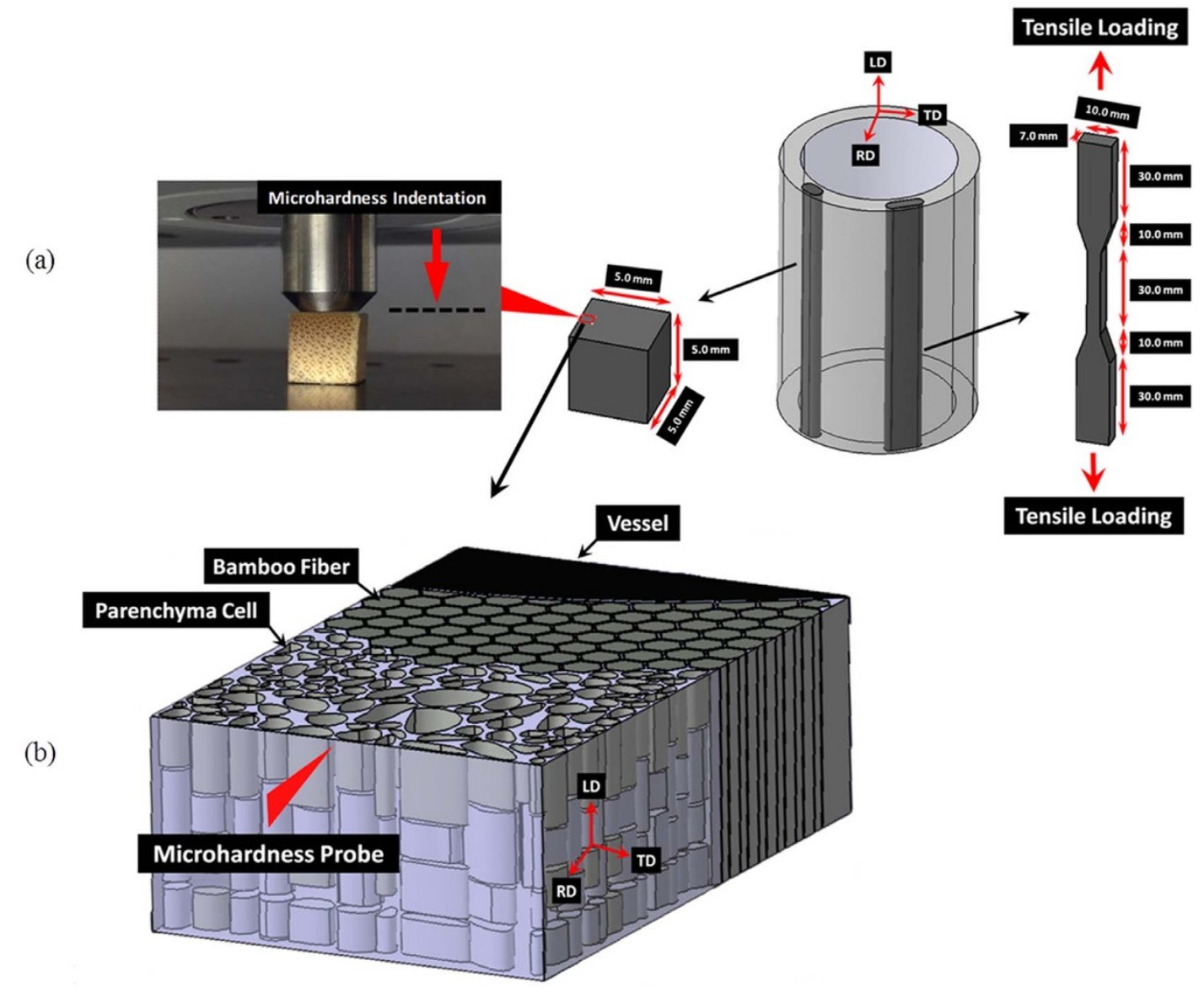

Figure $2 \mid$ Samples and experimental configuration. (a) microhardness (left, cubic) and tensile (right, dog-bone shaped) testing samples, along with the microhardness indentation configuration; (b) schematic representation of microhardness probe loading direction (the red arrow) with respect to a vascular bundle.

which were estimated to be $\mathrm{K}_{\mathrm{eff}}^{\mathrm{p}}(\mathrm{RD}) \sim(0.75-0.95) \mathrm{K}_{\mathrm{I}}^{\mathrm{p}}$ and $\mathrm{K}_{\text {eff }}^{\mathrm{f}}(\mathrm{RD}) \sim(0.75-0.85) \mathrm{K}_{\mathrm{I}}^{\mathrm{f}}$, for the parenchyma matrix $\left(\mathrm{K}^{\mathrm{P}}\right)$ alone and fiber bundles $\left(\mathrm{K}^{\mathrm{f}}\right)$ alone, respectively. Similarly, along the LD, the effective stress intensity factors were estimated to be $\mathrm{K}_{\text {eff }}^{\mathrm{p}}(\mathrm{LD}) \sim(0.5) \mathrm{K}_{\mathrm{I}}^{\mathrm{p}}$ and $\mathrm{K}_{\text {eff }}^{\mathrm{f}}(\mathrm{LD}) \sim(0.5) \mathrm{K}_{\mathrm{I}}^{\mathrm{f}}$ for the parenchyma matrix $\left(\mathrm{K}^{\mathrm{P}}\right)$ and fiber bundles $\left(\mathrm{K}^{\mathrm{f}}\right)$, respectively. The reduction in overall effective stress intensity factor owing to the crack deflection by vessels could be likewise justified in a similar manner. Despite the different stress intensity factors $\left(\mathrm{K}_{\mathrm{eff}}\right)$ of bamboo's respective phases owing to structural heterogeneity, unlike polycrystalline solids, the combined effect according to aforementioned estimations and their interplays will result in an overall reduction of the driving force for crack propagation in the whole bamboo structure. Therefore, as demonstrated experimentally and validated numerically, the occurrence of interfacial fractures within the cellular parenchyma matrix as well as honeycomb fibers' bundles could be considerably responsible for bamboo's remarkable fracture toughness, along with the contribution from the hollow vessels. Lastly, it might be noted that, such interactions amongst the structural features and a propagating crack has been likewise demonstrated for other plant tissues: for example, in Yew and Spruce wood, fibers with different shapes and sizes retard the crack growth via fiber bridging whereas the holes within the structure arrest the crack in the course of its propagation ${ }^{18}$, while in the case of Green Sapwood (Pinus Sylvestris), crack propagation often occurs through the middles lamella of earlywood, causing deflection around the cells, followed by arresting as it approaches the latewood layers ${ }^{19}$.
Conclusions. In summary, the remarkable mechanical behavior of bamboo is stemmed out from the hierarchical configuration of parenchyma ground as the matrix along with fibers as the reinforcement. The occurrence of interfacial fractures within the cellular parenchyma matrix along with honeycomb structure of fibers in both radial and longitudinal directions is mainly responsible for the remarkable fracture toughness of bamboo by reducing the overall effective stress intensity factor. Likewise, the hollow vessels within the bamboo culm can further tailor the fracture properties by deflecting crack growth or absorbing cracktip energy. Therefore a complete picture showing the tortuous crack propagation mode in bamboo's hierarchical cellular structure has been unambiguously disclosed. It is expected that the present experimental findings concerning the bamboo's unique structural features versus its mechanical behavior shall be quite helpful in creating biomimicking structural designs along with the development of futuristic advanced composites.

\section{Methods}

Sample preparation and microstructure characterization. The moso or mao zhu bamboo (Phyllostachys edulis species), collected from raw bamboo plantations located in Jiangsu and Zhejiang provinces in China, were selected for this study. The samples were all mature bamboo ( $\sim 5$ years old $)$ freshly cut from the middle section of stalk, and were kept at room temperature of $\sim 23^{\circ} \mathrm{C}$ and relative humidity of $\sim 55-$ $65 \%$ (reasonably close to the humidity level of moso bamboo's natural habitat) to avoid drying artifacts. Microstructural characterizations were conducted on the polished bamboo samples taken from both radial/transverse and longitudinal sections, to reveal the microstructure of different constituents. The characterizations were further continued to investigate the crack growth modes in the case of microhardness indentation-induced cracks along with fracture surface analysis after 
(a)
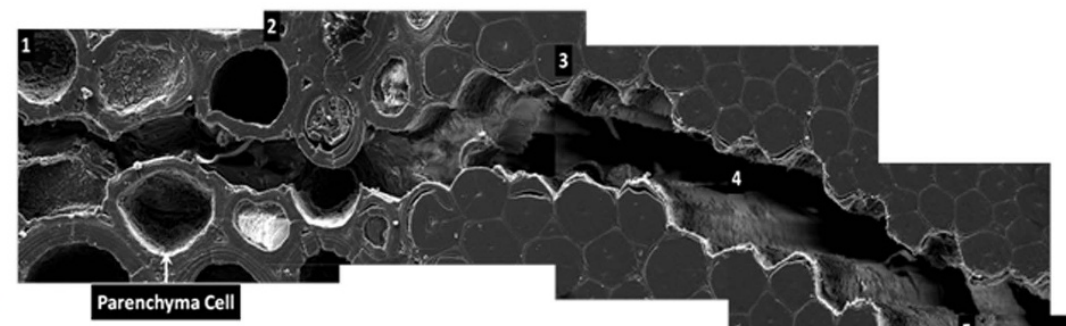

เธ

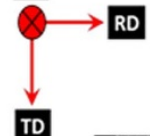

ID
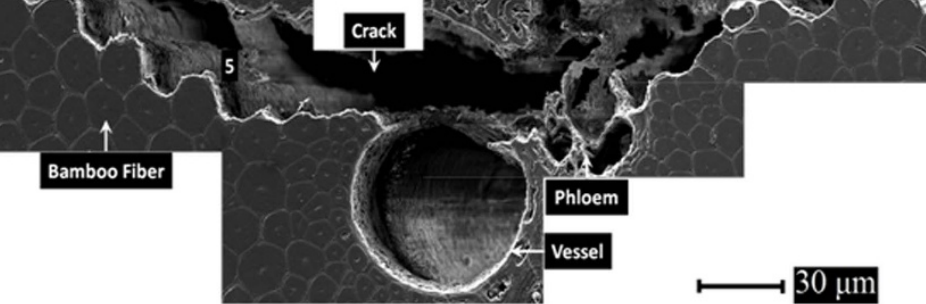

(b)
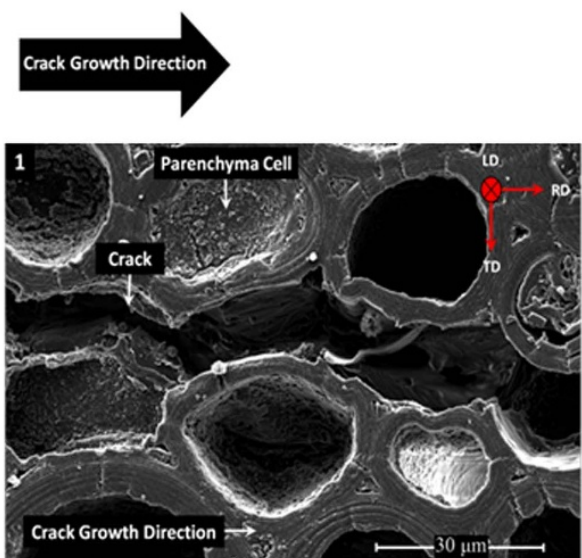

(e)

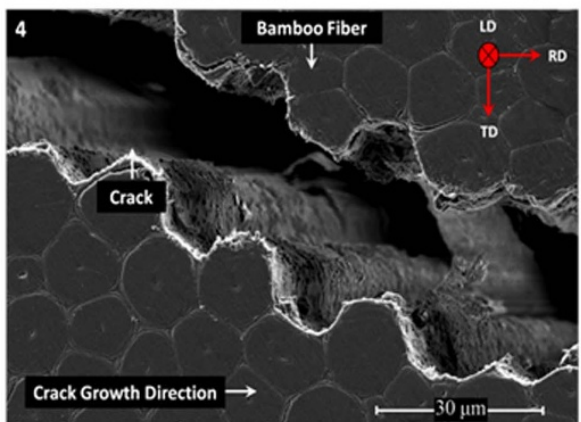

(c)

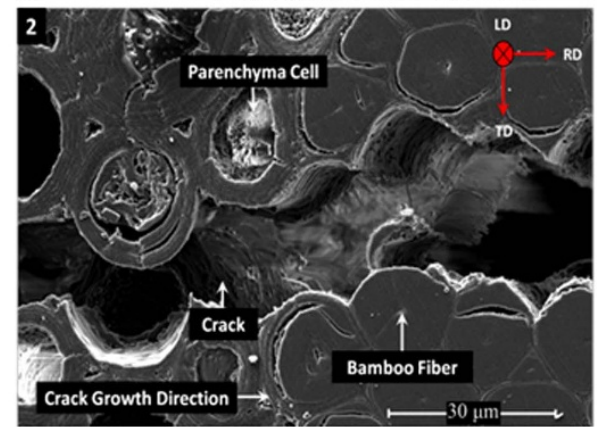

(d)

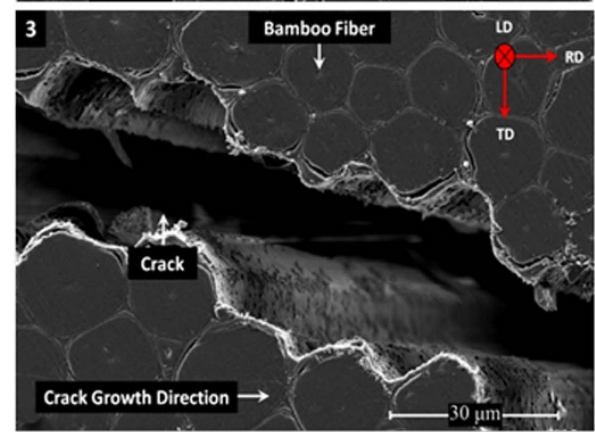

(i)

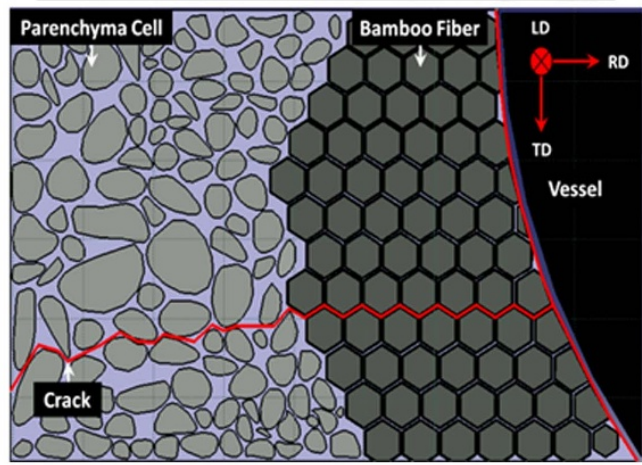

(f)

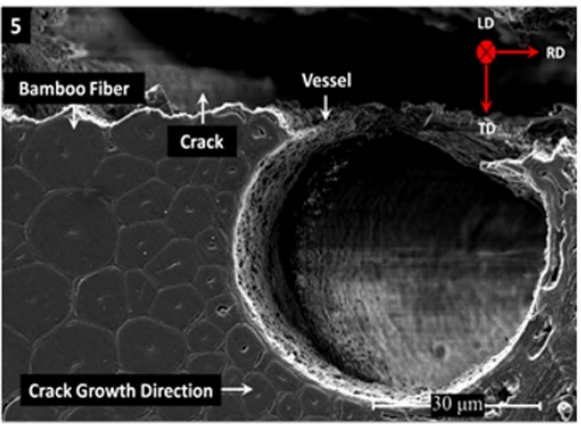

(g)
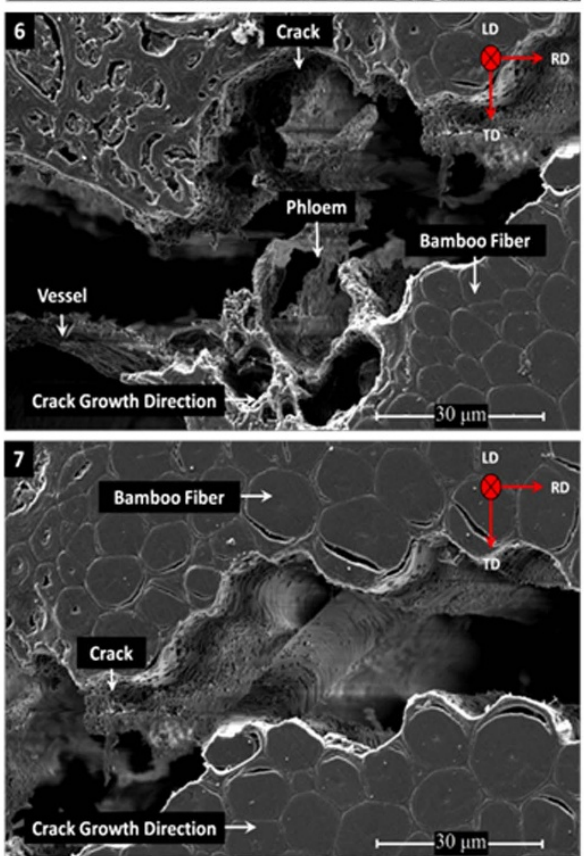

Figure 3 Microhardness indentation-induced crack growth in bamboo culm (a), along with: (b-h) high magnification micrographs representing the crack propagation within the corresponding constituents $((\mathrm{b}-\mathrm{c})$ : parenchyma cells; $(\mathrm{c}-\mathrm{e})$ : fibers; $(\mathrm{f}-\mathrm{g})$ : a hollow vessel; ( $\mathrm{g}-\mathrm{h})$ : fibers); (i) schematic representation of the indention-induced crack growth within different constituents of bamboo in radial direction (RD). 


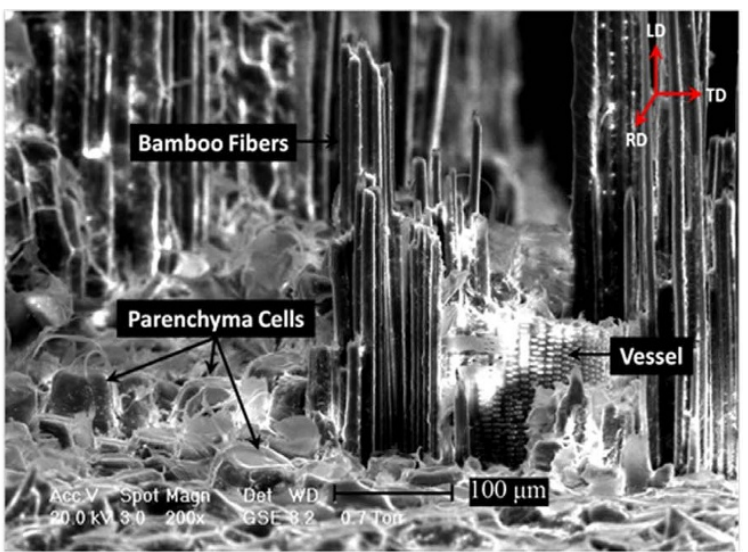

(b)
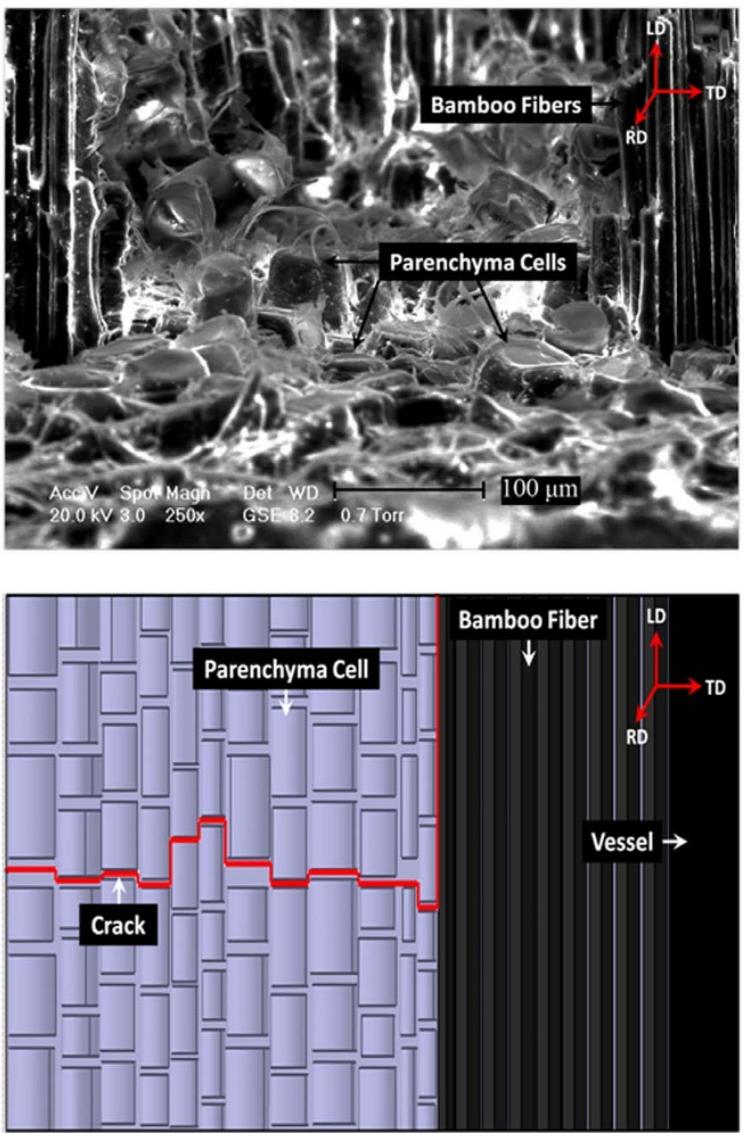

Figure $4 \mid$ Crack propagation in bamboo culm's three-dimensional (3D) structure revealed by a tensile fractured sample: $(\mathrm{a}-\mathrm{b})$ ESEM micrographs displaying the tensile fracture surfaces of the bamboo culm at high magnification, with focus on the (a) fibers pull-out and the (b) intact parenchyma cells; (c) schematic representation of crack growth within bamboo's different constituents from the view of longitudinal direction (LD).

tensile deformations. For this purpose, a Philips ${ }^{\mathrm{TM}}$ XL30 FEG Environmental Scanning Electron Microscope (ESEM) along with a FEI Quanta ${ }^{\mathrm{TM}} 450$ FEG Scanning Electron Microscope working at ESEM mode were used. The captured micrographs were also processed by TalyMap ${ }^{\mathrm{TM}}$ Universal image analyzer software to quantify the volume fractions of bamboo's different constituents.

Mechanical characterizations. To investigate the interactions of different constituents alongside their corresponding interfacial areas with a developed crack, cracks were intentionally initiated along the radial direction (RD) of bamboo culms by a Fischerscope ${ }^{\mathrm{TM}}$ HM2000 microhardness tester. For this purpose, a small cubic sample was subjected to microhardness indenter with an indentation load of $2000 \mathrm{mN}$ (see Fig. 2a-b). Later on, to further validate the observed indentationinduced crack growth mode, tensile experiment was conducted on an intact dog-bone shaped sample, prepared from bamboo's longitudinal direction (LD, see Fig. 2a), by using a MTS Alliance ${ }^{\mathrm{TM}}$ RT/30 Material Testing System. Similar to indentationinduced crack, pulling the dog-bone bamboo samples along the LD opened up a fracture surface along the $\mathrm{RD}$ which subsequently led to the crack propagation and fracture failure. Lastly, to obtain a quantitative understanding of bamboo's different constituents' mechanical properties, nanoindentation and micro-tensile tests were also performed. For nanoindentation experiments, a Hysitron TI $750 \mathrm{Ubi}^{\mathrm{TM}}$ nanoindenter with a calibrated cube-corner tip (curvature radius $\sim 100 \mathrm{~nm}$ ) was employed. Load control experiments were used to indent the polished surface of individual fibers along with parenchyma cells, respectively. For micro-tensile tests on individual fibers, a Gatan Microtest ${ }^{\mathrm{TM}} 200$ tensile tester with $2 \mathrm{~N}$ load cell (resolution $0.001 \mathrm{~N}$ ) was used under displacement control mode at a constant rate of $0.1 \mathrm{~mm} /$ min. All mechanical characterizations were conducted on as received samples at ambient laboratory environment (temperature $\sim 23^{\circ} \mathrm{C}$ and relative humidity $\sim 50-$ $60 \%$, respectively), to simulate natural bamboo's realistic deformation conditions. To further validate the crack propagation mode in natural bamboo with even higher moisture content, additional experiments for bamboo with high humidity $(\sim 75$ $85 \%$ ) were performed (results shown in the Supplementary Information), by microhardness indentation experiments on pre-moisturized samples from high-humidity environment (relative humidity $\sim 90 \%$, kept for overnight, $>12$ hours).

1. Yu, Y., Jiang, Z., Fei, B., Wang, G. \& Wang, H. An improved microtensile technique for mechanical characterization of short plant fibers: A case study on bamboo fibers. J. Mater. Sci. 46, 739-746 (2011).

2. Lo, T. Y., Cui, H. Z. \& Leung, H. C. The effect of fiber density on strength capacity of bamboo. Mater. Letts. 58, 2595-2598 (2004).

3. Li, S. H., Zeng, Q. Y., Xiao, Y. L., Fu, S. Y. \& Zhou, B. L. Biomimicry of bamboo bast fiber with engineering composite materials. Mater. Sci. Eng. C 3, 125-130 (1995),

4. Wang, X., Ren, H., Zhang, B., Fei, B. \& Burgert, I. Cell wall structure and formation of maturing fibres of moso bamboo (Phyllostachys pubescens) increase buckling resistance. J. R. Soc. Interface. 9, 988-996 (2012).

5. Wegst, U. G. Bamboo and wood in musical instruments. J. Mater. Res. 38, 323 (2008).

6. Gerhardt, M. R. Microstructure and mechanical properties of bamboo in compression. Massachusetts Institute of Technology (2012).

7. Zou, L., Jin, H., Lu, W. Y. \& Li, X. Nanoscale structural and mechanical characterization of the cell wall of bamboo fibers. Mater. Sci. Eng. C 29, 1375-1379 (2009).

8. Low, I. M., Che, Z. Y. \& Latella, B. A. Mapping the structure, composition and mechanical properties of bamboo. J. Mater. Res. 21, 1969-1976 (2006).

9. Amada, S., Ichikawa, Y., Munekata, T., Nagase, Y. \& Shimizu, H. Fiber texture and mechanical graded structure of bamboo. Compos. Part B-Eng. 28, 13-20 (1997).

10. Tan, T. et al. Mechanical properties of functionally graded hierarchical bamboo structures. Acta Biomater. 7, 3796-3803 (2011).

11. Gibson, L. J. The hierarchical structure and mechanics of plant materials. J. R. Soc Interface. 9, 2749-2766 (2012).

12. Silva, E. C. N., Walters, M. C. \& Paulino, G. H. Modeling bamboo as a functionally graded material: Lessons for the analysis of affordable materials. J. Mater. Sci. 41, 6991-7004 (2006).

13. Chung, K. F. \& Yu, W. K. Mechanical properties of structural bamboo for bamboo scaffoldings. Eng. Struct. 24, 429-442 (2002).

14. Shao, Z.-P., Fang, C.-H. \& Tian, G.-L. Mode I interlaminar fracture property of moso bamboo (Phyllostachys pubescens). Wood Sci. Technol. 43 (2009).

15. Amada, S. \& Untao, S. Fracture properties of bamboo. Compos. Part B-Eng. 32, 451-459 (2001)

16. Hanlon, T., Tabachnikova, E. D. \& Suresh, S. Fatigue behavior of nanocrystalline metals and alloys. Int. J. Fatigue. 27, 1147-1158 (2005).

17. Suresh, S. Fatigue crack deflection and fracture surface contact: Micromechanical models. Metall. Trans. A 16, 249-260 (1985).

18. Stanzl-Tschegg, S. E., Keunecke, D. \& Tschegg, E. K. Fracture tolerance of reaction wood (yew and spruce wood in the TR crack propagation system). J. Mech Behav Biomed Mater. 4, 688-698 (2011).

19. Thuvander, F. \& Berglund, L. A. In situ observations of fracture mechanisms for radial cracks in wood. J. Mater. Sci. 35, 6277-6283 (2000).

\section{Acknowledgments}

The authors gratefully thank Prof. Lorna J. Gibson and Dr. Ming Dao (Department of Materials Science and Engineering, MIT) for the valuable discussions and insightful comments. The authors also thank Xiaowei Liu for the help on micro-tensile experiments. M.K. Habibi acknowledges the support from CityU International Transition Team Scheme (ITT-GTA) Postdoctoral Fellowship. This work was supported by City University of Hong Kong Seed Grant Project \# 7003021

\section{Author contributions}

M.K.H. and Y.L. conceived the concepts of the research and designed the experiments M.K.H. prepared the samples and performed the experiments. M.K.H. and Y.L. analyzed the data and composed the manuscript. 


\section{Additional information}

Supplementary information accompanies this paper at http://www.nature.com/ scientificreports

Competing financial interests: The authors declare no competing financial interests.

How to cite this article: Habibi, M.K. \& Lu, Y. Crack Propagation in Bamboo's Hierarchical Cellular Structure. Sci. Rep. 4, 5598; DOI:10.1038/srep05598 (2014). cc) (i) $\Theta$ This work is licensed under a Creative Commons Attribution-NonCommercialNoDerivs 4.0 International License. The images or other third party material in this article are included in the article's Creative Commons license, unless indicated otherwise in the credit line; if the material is not included under the Creative Commons license, users will need to obtain permission from the license holder in order to reproduce the material. To view a copy of this license, visit http:// creativecommons.org/licenses/by-nc-nd/4.0/ 